\title{
The emergence of insecticide resistance in central Mozambique and potential threat to the successful indoor residual spraying malaria control programme
}

Ana P Abilio ${ }^{1}$, Immo Kleinschmidt ${ }^{2}$, Andrea M Rehman ${ }^{2}$, Nelson Cuamba ${ }^{1}$, Varsha Ramdeen ${ }^{3}$, David S Mthembu ${ }^{3}$, Sarel Coetzer ${ }^{3}$, Rajendra Maharaj ${ }^{3}$, Craig S Wilding ${ }^{4}$, Andrew Steven ${ }^{4}$, Marlize Coleman ${ }^{4}$, Janet Hemingway ${ }^{4}$ and Michael Coleman ${ }^{*}$

\begin{abstract}
Background: Malaria vector control by indoor residual spraying was reinitiated in 2006 with DDT in Zambézia province, Mozambique. In 2007, these efforts were strengthened by the President's Malaria Initiative. This manuscript reports on the monitoring and evaluation of this programme as carried out by the Malaria Decision Support Project.
\end{abstract}

Methods: Mosquitoes were captured daily through a series of 114 window exit traps located at 19 sentinel sites, identified to species and analysed for sporozoites. Anopheles mosquitoes were collected resting indoors and tested for insecticide resistance following the standard WHO protocol. Annual cross sectional household parasite surveys were carried out to monitor the impact of the control programme on prevalence of Plasmodium falciparum in children aged 1 to 15 years.

Results: A total of 3,769 and 2,853 Anopheles gambiae s.l. and Anopheles funestus, respectively, were captured from window exit traps throughout the period. In 2010 resistance to the pyrethroids lambda-cyhalothrin and permethrin and the carbamate, bendiocarb was detected in An. funestus. In 2006, the sporozoite rate in An. gambiae s.s. was $4 \%$ and this reduced to $1 \%$ over 4 rounds of spraying. The sporozoite rate for An. funestus was also reduced from $2 \%$ to 0 by 2008. Of the 437 Anopheles arabiensis identified, none were infectious. Overall prevalence of $P$. falciparum in the sentinel sites fell from 60\% to 32\% between October 2006 and October 2008.

Conclusion: Both An. gambiae s.s. and An. funestus were controlled effectively with the DDT-based IRS programme in Zambézia, reducing disease transmission and burden. However, the discovery of pyrethroid resistance in the province and Mozambique's policy change away from DDT to pyrethroids for IRS threatens the gains made here.

\section{Background}

The Roll Back Malaria, United Nations Millennium Development Goals and World Health Assembly universal access and coverage targets for malaria prevention and treatment have been established to reduce disease transmission. To meet these targets malaria control interventions are now being scaled up [1,2].

\footnotetext{
* Correspondence: mcoleman@liverpool.ac.uk

${ }^{4}$ Liverpool School of Tropical Medicine, Pembroke Place, Liverpool. L3 5QA, UK

Full list of author information is available at the end of the article
}

To successfully control malaria, programmes must use current tools efficiently. In moderate to high transmission areas this requires the combination of effective vector interventions, either indoor residual spraying of insecticides (IRS) and/or insecticide-treated nets (ITNs), with effective drug treatment. To achieve this, continuous surveillance, monitoring and evaluation ( $\mathrm{M} \& \mathrm{E})$ need to be integrated into the malaria control programme. There are very few examples of good malaria $M$ \& E, which include parasitological, disease transmission and entomological data assessment. These include Bioko

\section{() Biomed Central}


island [3,4], the cross border Lubombo Spatial Development Initiative (LSDI) [5], Eritrea [6] and Zambia [7].

In Mozambique, the National Malaria Control Programme (NMCP) used DDT for IRS before a change in policy in 1993, when the pyrethroid lambda-cyhalothrin was introduced in the southern part of the country. With the discovery of Anopheles funestus resistant to pyrethroids in South Africa [8], the LSDI implemented an insecticide resistance monitoring programme in southern Mozambique that showed in 1999 that both An. funestus and Anopheles arabiensis were resistant to pyrethroids $[9,10]$ due to elevated p450s [11]. This resulted in an informed insecticide policy change to the carbamate bendiocarb for IRS [5]. Bendiocarb was sprayed biannually in southern Mozambique until 2005, when, due to the high economic costs associated with this insecticide, an operational change was made back to DDT. No resistance has yet been detected to DDT in Mozambique.

In 2005 the U.S. Government initiated the President's Malaria Initiative (PMI) [12], which supported the rapid scale-up of malaria prevention and treatment in 15 countries in Africa, including Mozambique. In central Mozambique, an IRS programme was initiated in six districts in Zambézia province. Previously, the NMCP had carried out vector control with sporadic IRS and fogging between 1995 and 2003 in this area. In 2005, the NMCP resumed IRS in Zambézia in three districts, using DDT. Limited expansion of activities occurred in 2006 to cover 5 districts and this effort was strengthened in 2007 by PMI. The IRS was focused on densely populated areas using DDT or lambda-cyhalothrin, the latter being applied on structures not suitable for DDT (i.e. finished or painted walls). In 2009, pyrethroids were the sole class of insecticides purchased for IRS, although all remaining stocks of DDT were sprayed during that year [13].

Zambézia province was used to pilot and refine a new Malaria Decision Support System (MDSS) [14], which was implemented in 19 sentinel sites in Zambézia province in 2006 and served to evaluate and monitor the interventions described above. The objective of this work was to determine whether the system, which was continuously improved during the course of the study, could be deployed in a resource poor setting, with low level infrastructure and limited human capacity. The utility to control programme managers of an integrated surveillance system providing real time monitoring through a number of performance and impact indicators, was clearly demonstrated.

\section{Methods}

\section{Study site and insecticide usage}

In 2006, 19 sentinel sites were established in six districts in Zambézia province, Mozambique. IRS with DDT (Hindustan Insecticide limited, New Delhi, India) was carried out in Oct/Nov 2006 and subsequently each year in all districts except for Maganja da Costa, where LLINs (both Olyset, Sumitomo Chemical and Permanent, Vestergaard Frandsen) were distributed from 2009 (Figure 1). Entomological surveillance and cross-sectional malaria indicator surveys were carried out at all 19 sites.

\section{Insecticide resistance testing}

Indoor resting blood fed adult female Anopheles gambiae s.l and An. funestus for insecticide resistance bioassays were collected between hours 06.00-10.00 in houses using an aspirator during the period Oct 2006 to May 2010. Until 2009, wild caught mosquitoes were used for insecticide susceptibility assays following the WHO insecticide susceptibility test protocol (WHO 1998). Assays carried out on wild-caught mosquitoes did not allow for standardisation in age, physiological state or pre-exposure to insecticides. After the establishment of an insectary in 2009, wild-caught female mosquitoes were transported to the laboratory, kept in individual oviposition tubes with access to $10 \%$ sucrose and allowed to lay eggs. Each family was reared separately through to 1-3 day old $\mathrm{F} 1$ adults at $26^{\circ} \mathrm{C}+/-2^{\circ} \mathrm{C}$ and $70-80 \%$ relative humidity allowing standardisation of age physiological state and testing conditions. Families were mixed prior to testing to avoid bias from isofemale lines where offspring may all be genetically similar. Between five and 25 adult mosquitoes were exposed to insecticide treated or control papers, impregnated with the carrier oil alone, for 1 hour and then transferred to holding tubes with access to $10 \%$ sugar solution for 24 hours before the percentage mortality was determined. The insecticides tested were, deltamethrin $(0.05 \%)$, lambda-cyhalothrin $(0.05 \%)$, bendiocarb $(0.01 \%)$, and DDT (4\%). All papers were supplied by WHO.

\section{Species abundance and sporozoite rates}

Prior to the initiation of IRS in 2006 a window exit trap was installed in six houses at each sentinel site with the home-owner's permission. Home-owners were trained to empty the traps daily into pre-labelled specimen jars containing isopropanol and complete checklists indicating the nights for which the traps were checked.

\section{Species identification}

Wild-caught females were morphologically identified as belonging to the An. gambiae s.l. complex or An. funestus s.l. group $[15,16]$. Species identification within each complex was carried out by DNA-polymerase chain reaction on a sample of specimens $[17,18]$.

\section{Sporozoite identification}

DNA was extracted from the head and thorax of a subsample of mosquitoes using the Livak method [19] and 


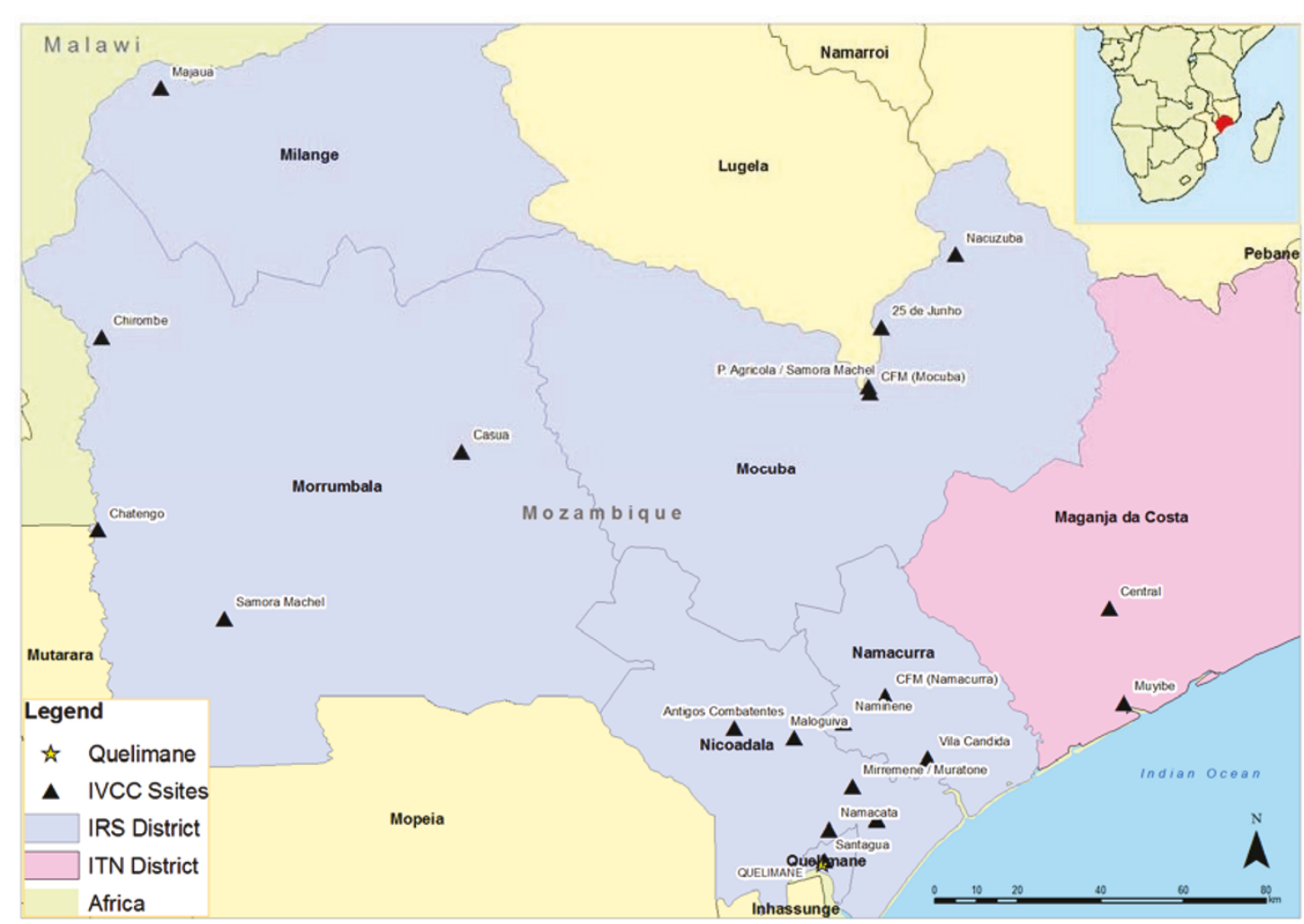

Figure 1 Map showing the location of sentinel sites in Zambézia province, Mozambique.

infection with Plasmodium species was determined using a multiplex real time PCR [20].

\section{Household surveys}

Cross sectional household surveys based on the malaria indicator survey of the Roll Back Malaria Monitoring and Evaluation Reference Group [21] were carried out at each sentinel site on a random sample of 140 children between 1 and 15 years of age. Households were selected from strata formed by dividing sentinel sites into quadrants from which participants were selected, to ensure the greatest geographical spread within the site. Diagnostic tests with ICT ${ }^{\mathrm{TM}}$ malaria rapid tests (ICT, Global Diagnostics, Cape Town, South Africa.) were used to assess the Plasmodium falciparum infection status of each of the sampled children. Participants who tested positive were offered treatment with Coartem ${ }^{\circledR}$ (Novartis) (artemether and lumefantrine) according to Mozambique's national malaria treatment guidelines.

Household surveys were carried out prior to the initiation of IRS in October 2006 and subsequently in the same month in 2007 and 2008. The sentinel site-specific sample size was calculated to provide evidence at the $5 \%$ significance level of an absolute reduction in P. falciparum prevalence of $20 \%$ following the intervention. Prevalence and 95\% confidence intervals (CI) for each sentinel site were estimated taking account of clustering by sentinel site using the statistical software package STATA (StataCorp LP. Stata Statistical Software: Release 10. College Station, TX, USA.).

Sentinel sites were considered the primary sampling unit. Logistic regression, allowing for complex survey designs, was performed to estimate the mean effect of the intervention on prevalence compared to baseline prevalence of infection in different years.

\section{Ethics}

Ethics was approved for this work by the Ministry of Health, Mozambique Reg: 3622/IMS-2/DNS/06.

\section{Results}

\section{Vector abundance and transmission}

Over the 44 month study period, a total of 6,622 anophelines were collected from 114 window exit traps that operated continuously. Three thousand seven hundred and sixty nine were morphologically identified as $A n$. gambiae s.l. and 2,853 as An. funestus. Of these, 905 An. gambiae s.l. and 946 An. funestus were further identified to species level and tested for sporozoites (Table 1). Anopheles gambiae and An. arabiensis were the only two members of the An. gambiae complex and $A n$. funestus s.s the only member of the An. funestus group 
Table 1 Abundance, sporozoite rate and relative transmission index of specimens collected over a two years period, at all sentinel sites in Zambézia province, 2006-2010.

\begin{tabular}{|c|c|c|}
\hline & Period 1 & Period 2 \\
\hline & $\begin{array}{l}2006 \text { to } \\
2007\end{array}$ & $\begin{array}{l}2009 \text { to } \\
2010\end{array}$ \\
\hline \multicolumn{3}{|l|}{ An. gambiae s.l } \\
\hline No Caught & 2304 & 1465 \\
\hline $\begin{array}{l}\text { No analyzed for species } \\
\text { identification }\end{array}$ & 456 & 449 \\
\hline Proportion An. gambiae s.s (\%) & 91 & 63 \\
\hline Proportion An. arabiensis (\%) & 5 & 22 \\
\hline \multicolumn{3}{|l|}{ An. Arabiensis } \\
\hline No estimated & 115 & 322 \\
\hline No per trap per 100 nights & 0.058 & 0.2 \\
\hline Sporozoite rate (\%) & $0(n=24)$ & $0(n=98)$ \\
\hline Transmission index & NA & NA \\
\hline $\begin{array}{l}\text { Transmission index relative to } \\
\text { baseline }\end{array}$ & 1 & NA \\
\hline \multicolumn{3}{|l|}{ An. gambiae s.s } \\
\hline No estimated & 2097 & 923 \\
\hline No per trap per 100 nights & 0.997 & 0.59 \\
\hline Sporozoite rate (\%) & $\begin{array}{c}4.096(n= \\
415)\end{array}$ & $\begin{array}{l}1.053(n= \\
285)\end{array}$ \\
\hline Transmission index & 0.0486 & 0.0062 \\
\hline $\begin{array}{l}\text { Transmission index relative to } \\
\text { baseline }\end{array}$ & 1 & 0.13 \\
\hline \multicolumn{3}{|l|}{ An. funestus S.S } \\
\hline No Caught & 1997 & 856 \\
\hline No per trap per 100 nights & 1.59 & 0.19 \\
\hline Sporozoite rate (\%) & $\begin{array}{c}2.272(n= \\
660)\end{array}$ & $0(n=272)$ \\
\hline Transmission index & 0.036 & NA \\
\hline $\begin{array}{l}\text { Transmission index relative to } \\
\text { baseline }\end{array}$ & 1 & NA \\
\hline
\end{tabular}

$\mathrm{NA}=$ Not Applicable

to be identified. Anopheles gambiae s.s. was the predominant species in all spray round periods from the window exit trap collections (Figure 2, Table 1).

Between 2006 and 2010 there was a steady decline in the abundance of An. gambiae s.l. and An. funestus with the estimated number of An. gambiae per window trap per 100 nights falling from 10 to 0.59 and An. funestus declining from 1.59 per window trap per 100 nights to 0.2. A spike in An. funestus abundance (May to Oct 2007) occurred only in Maganja da Costa where control operations were minimal in 2007. Prior to the LLIN distribution in Maganja da Costa in 2008 the abundance of An. gambiae s.l and An. funestus was 52.2 and 88.6 per window trap per 100 nights respectively. This number

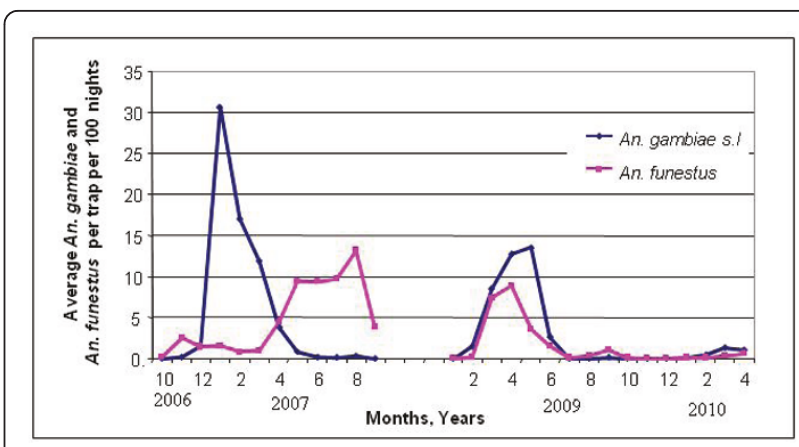

Figure 2 An. gambiae s.l. and An. funestus species abundance from all 19 sentinel sites combined. Collections did not occur 09 2007 to 012009 due to logistical problems.

was reduced dramatically to 2.7 in 2009 and 1.6 in 2010 for An. gambiae s.l. and to zero for An. funestus for both 2009 and 2010 (data not tabulated). The proportion of An. arabiensis increased from 5\% to $15 \%$ of the total An. gambiae s.l. complex caught.

In the period 2006 to 2007, combined sporozoite rates across all IRS districts were $4.1 \%$ and $2.3 \%$ for An. gambiae s.s and An. funestus respectively. After four rounds of IRS this was reduced to 1\% for An. gambiae s.s and to zero for $A n$. funestus in the 2009 to 2010 period (Table 1). No infective An. arabiensis were identified pre- or post-intervention.

The relative transmission index, defined as the ratio of infective anopheline abundance, relative to the baseline period of 2006/7 was 0.13 for An. gambiae s.s. for the follow-up period 2009/10. After three spray rounds no infected An. funestus s.s were caught, so no transmission index could be calculated.

\section{Insecticide resistance}

A total of 3,664 Anopheles were tested for insecticide resistance between April 2006 and April 2010, of which 1,471 were wild-caught adult mosquitoes prior to the establishment of an insectary, and 1,786 were F1 generation mosquitoes from 105 families after an insectary was established. After the implementation of IRS in Zambézia province, the number of mosquitoes collected in the field was significantly reduced making collections difficult for resistance testing and resulting in only 13 of the 19 sites being tested (Table 2).

No resistance to any of the insecticides tested was detected in the province prior to 2010. In 2010, resistance to the carbamate, bendiocarb and the pyrethroid, lambda-cyhalothrin was detected in F1 generation $A n$. funestus from Majaua (84.5\% and $82.9 \%$ mortality respectively) and Mugeba (93.5\% and $76.2 \%$ mortality respectively). A low level of survival to the pyrethroid permethrin was also detected in An. funestus from 
Table 2 WHO susceptibility test result on wild-caught adult female mosquitoes from 2006 to 2008 and one-three day old female F1 generation from 2010, for Anopheles funestus and Anopheles gambiae s.I from different localities of Zambézia province Mozambique

\begin{tabular}{|c|c|c|c|c|c|c|c|c|c|c|}
\hline \multirow{3}{*}{ Locality } & \multicolumn{10}{|c|}{2006 to 2008} \\
\hline & \multicolumn{2}{|c|}{ Bendiocarb $(0.01 \%)$} & \multicolumn{2}{|c|}{ DDT (4\%) } & \multicolumn{2}{|c|}{ Deltamethrin $(0.05 \%)$} & \multicolumn{2}{|c|}{ Lamba cyhalothrin $(0.05 \%)$} & \multicolumn{2}{|c|}{ Permethrin $(0.75 \%)$} \\
\hline & $\% \mathrm{M}$ & $\mathbf{n}$ & $\% M$ & $\mathbf{n}$ & $\% \mathrm{M}$ & $\mathbf{n}$ & $\% \mathrm{M}$ & $\mathbf{n}$ & $\% \mathrm{M}$ & $\mathrm{n}$ \\
\hline \multicolumn{11}{|l|}{ An. funestus } \\
\hline Quelimane & & & & & 100 & 28 & 100 & 50 & & \\
\hline A. combatentes & & & 100 & 25 & 100 & 25 & & & & \\
\hline Namacurra & & & 100 & 20 & & & & & & \\
\hline Maganja da Costa & 100 & 22 & 100 & 60 & 100 & 85 & 100 & 74 & & \\
\hline Muibi & 100 & 28 & 100 & 45 & 100 & 5 & 100 & 11 & & \\
\hline CFM-Mocuba & & & 100 & 59 & 100 & 78 & & & & \\
\hline Posto Agricola & & & 100 & 209 & 100 & 121 & & & & \\
\hline 25 de Junho & & & 100 & 79 & 100 & 31 & & & & \\
\hline \multicolumn{11}{|l|}{ Mugeba } \\
\hline \multicolumn{11}{|l|}{ Majaua } \\
\hline \multicolumn{11}{|l|}{ An. gambiae s.l } \\
\hline Quelimane & 100 & 91 & & & 100 & 15 & 100 & 130 & 100 & 4 \\
\hline Nicoadala & 100 & 60 & & & & & 100 & 56 & & \\
\hline Central & & & 100 & 30 & 100 & 30 & & & & \\
\hline \multicolumn{11}{|l|}{ Muibi } \\
\hline \multicolumn{11}{|l|}{ Nacuzuba } \\
\hline & & & & & & 2010 & & & & \\
\hline \multicolumn{11}{|l|}{ An. funestus } \\
\hline Mugeba & 93.5 & 229 & 100 & 224 & & & 76.2 & 234 & 99.4 & 197 \\
\hline Majaua & 84.5 & 207 & 100 & 193 & & & 82.9 & 159 & 100 & 193 \\
\hline \multicolumn{11}{|l|}{ An. gambiae s.l. } \\
\hline Muibi & & & 100 & 29 & & & 100 & 14 & & \\
\hline Nacuzuba & & & 100 & 44 & & & 100 & 43 & 100 & 20 \\
\hline
\end{tabular}

Majaua (99.4\% mortality) which requires further investigation (Table 2). No resistance was detected in An. gambiae. All species remained fully susceptible to DDT.

\section{Malaria prevalence}

A total of 4,864 children between one and 15 years of age were surveyed in 2006 for $P$. falciparum infection. Follow-up surveys were carried out in 2007 and 2008 involving 5,314 and 5,258 children respectively from the same sentinel sites. The refusal rate was not recorded but was negligible. Combined prevalence of infection with $P$. falciparum across all 19 sites surveyed in October 2006 was $52.3 \%(\mathrm{CI}=40.62-63.6)$, ranging from $24.8 \%(\mathrm{CI}=15.32-37.46)$ in Quelimane, the urban provincial capital, to $77.2 \%(\mathrm{CI}=50.7-91.7)$ in Morrumbala, the most rural area in this study. In 2007 overall prevalence for the same 19 sites showed no significant difference at $60.4 \%$ ( $\mathrm{CI}=50.54-69.56)$, however, for Maganja da Costa there was evidence of an increase in prevalence from $39 \%(\mathrm{CI}=22.7-58.2)$ to $76.1 \%(\mathrm{CI}=61.8-86.3, \mathrm{P}<$
0.05). In 2008 there was strong evidence of a reduction in combined prevalence for the region to $32 \%$ ( $\mathrm{CI}=$ 22.51-42.03) (Figure 3, Additional file 1), with the most significant reductions occurring in the more urban sites located in Nicoadala and Quelimane.

IRS coverage reached less than $50 \%$ of houses in the six districts targeted for spraying in 2007 due to limited resources. From 2008 the IRS programme was strengthened by PMI and IRS reached $>80 \%$ coverage of the 502,000 houses in the six target districts, comprising approximately 2 million persons.

\section{Discussion}

The success of the IRS-based LSDI programme in southern Mozambique [3] and the increase in malaria cases in northern Mozambique prompted the $\mathrm{MOH}$ and the NMCP to re-initiate a comprehensive vector control programme in Zambézia province. The MDSS project was embedded within the national programme, and demonstrated the feasibility and potential benefit of 

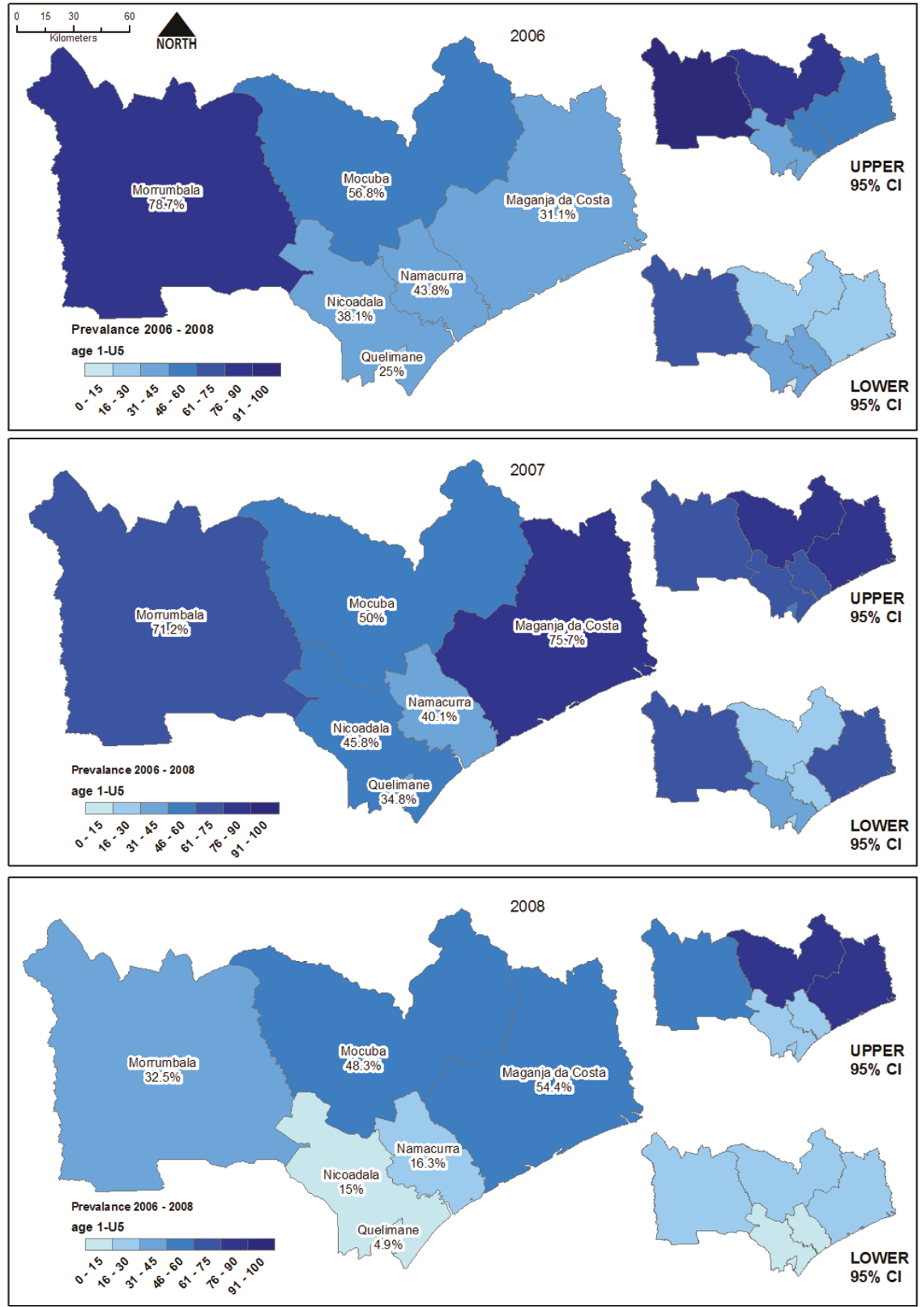

Figure 3 Temporal change in prevalence of $P$. falciparum in children 1 to 15 years of age between 2006 and 2009.

evaluating vector control interventions even in very resource poor settings. Intervention coverage and its impact on malaria vectors and on community prevalence of malarial infection were monitored as indicators of progress.
Anopheles gambiae s.s and An. funestus were the dominant malaria vector species in Zambézia province, where An. gambiae s.s. was predominant. This confirms results from previous studies of Anopheles distribution in northern Mozambique [22]. Although An. arabiensis 
was detected in this area, it was in low abundance with no sporozoite positive specimens found, indicating low transmission potential.

Mosquito species abundance changes naturally during annual cycles, depending on climatic variables [15,23]. Abundance of both An. gambiae s.s and An. funestus displayed seasonal variations, but were present throughout the year. An. gambiae peaked in January to May, at the height of the rainy season, whilst An. funestus was highest in April to August in 2007, towards the end of the rainy season, thus prolonging the malaria transmission season. However, in 2009, An. funestus peaked at the same time as $A n$. gambiae. With this potential pattern of vector abundance the vector control interventions need to remain effective for a duration of eight months each year. This requires either an insecticide with a long residual half-life, such as DDT, or spraying multiple rounds each year.

After three rounds of IRS with DDT a dramatic impact on vector populations was observed. This was similar to that reported for other IRS programmes, including the LSDI programme in southern Mozambique [5] and Bioko, Equatorial Guinea [3], where vector densities declined when effective insecticides were applied. In Zambézia, abundance of the vectors fell significantly from 1 to 0.6 and 1.6 to 0.2 per exit trap per 100 nights for $A n$. gambiae and An. funestus respectively. This corresponded with a reduction in the sporozoite rates from $4 \%$ to $1 \%$ in An. gambiae and 2\% to $0 \%$ in $A n$ funestus. While remaining low, numbers of $A n$. arabiensis collected after the interventions doubled, but as none of the samples tested positive for sporozoites, this species appears to have little or no involvement in malaria transmission. However, since An. arabiensis is known to be an effective malaria vector in other parts of Mozambique [5,24,25] and elsewhere, it is essential that this species continues to be monitored.

The vector control intervention has impacted on disease in the human population, as measured through prevalence surveys over three spray seasons. In the first year, IRS was carried out by the NMCP in Oct/Nov with limited resources. Only $50 \%$ of targeted houses were sprayed in each district. There was no measurable impact on disease prevalence in IRS sites after this intervention. In 2007 PMI support for the NMCP in this area was initiated, and IRS coverage increased to $>80 \%$, the rate recommend for effective IRS by WHO [26]. After this intervention there was a significant reduction in $P$. falciparum prevalence in children aged between one and 15 years in all IRS districts except Mocuba, where IRS had very little impact.

LLINs provide personnel protection, and with high coverage also offer community protection [27,28]. Data from Maganja da Costa (Additional file 1) show that a substantial decrease in parasite prevalence in the human population was associated with LLIN distribution in 2008. In this area, the abundance of An. gambiae and An. funestus declined from 52 and 88 per window trap per 100 nights to just 1.6 and 0 respectively. In 20062007, the rainfall was exceptionally high in this district leading to higher than usual rice cultivation in 2007. This may have resulted in increased vector abundance in the sentinel sites and increased transmission, which is reflected in the significant increase in prevalence in the 2007 survey. Since 2007, there has been limited rainfall, resulting in no rice cultivation. Both changes in rainfall pattern $[29,30]$ and alteration in agricultural practises [31] will impact on the vector population, in this case to the advantage of malaria control. These severe climatic changes in Maganja da Costa make it difficult to assess the true impact of the LLIN distribution in this area over such a short time. Although not as severe, a climatic change was documented throughout the study area, and needs to be considered when interpreting the impact of interventions.

Prior to the detection of pyrethroid resistance in $A n$. funestus in 2010 in sentinel sites in Mocuba, no insecticide resistance had been detected in the malaria vectors in this region to any insecticide. A low frequency of resistance may have been masked, as WHO discriminating doses are set at double the insecticide dose that gives $100 \%$ mortality of the least susceptible anopheline mosquitoes, making them good indicators of resistance only when resistance levels rise significantly in the mosquito population. Prior to 2010, and the establishment of an insectary in Zambézia, all resistance assays were carried out on wild-caught mosquitoes. This potentially affected resistance testing, as mosquitoes were not standardised for age, physiological state or pre exposure to insecticides. No DDT resistance was detected in the province. The detection of both bendiocarb and pyrethroid resistance at the same time, an unusual pattern of resistance, but one found in 2000 in southern Mozambique, thought initially to be due to cross resistance of elevated monooxygenase [11] but later data showed both elevated monooxygenase and altered acetylcholineesterase, a major mechanism of carbamate resistance, in $A n$. funestus populations [32] suggests that this resistance may have spread.

Monitoring insecticide resistance mechanisms is an integral component of resistance management, allowing for informed decisions on insecticide choice and resistance management [33], as a number of mechanisms may give rise to different cross resistance patterns $[34,35]$. Within the national programme over this time period it was not possible to monitor for resistance mechanisms, due to the lack of a cold chain to a suitable laboratory. New developments in molecular 
techniques should make this possible in the future $[36,37]$. However, as the resistance pattern observed in An. funestus here is very distinct, and similar to that previously detected in southern Mozambique [11,32,38], with resistance to both carbamates and pyrethroids segregating together it is likely that this resistance has not arisen de novo in central Mozambique. This has been shown to be the result of increased levels of monooxygenases and acetylcholinesterase in the same population $[32,38]$.

Currently Mozambique national policy has been to use lambda-cyhalothrin instead of DDT for IRS. The former was used in the 2009 spray round even though pyrethroid resistance has now been detected in Zambézia and previously in southern Mozambique [32,38-40].

In 1996, South Africa altered its insecticide of choice from DDT to the pyrethroid deltamethrin. After pyrethroid resistance was selected the recorded malaria cases increased more than six fold from 1995 to 1999. During this period there was also an increase in malaria drug resistance [41], but entomological surveys showed that An. funestus, which had previously been eliminated by DDT, had re-established in South Africa [8] from southern Mozambique due to the protection against IRS acquired through pyrethroid resistance. With the reintroduction of DDT [42] combined with the introduction of an effective drug [41] malaria control was once again successful in South Africa.

The recently detected low level pyrethroid resistance in An. funestus in Zambézia province reported here for the first time, and in neighbouring Likoma Island, Malawi, that is close to Zambezia [43], is likely to become operationally significant and should be closely monitored, as already there are anecdotal reports of $A n$. funestus resting in pyrethroid sprayed houses and an increase in malaria cases in Zambézia province.

\section{Conclusion}

The IRS-based vector control programme has had a successful impact on the malaria burden in Zambézia province. The effectiveness of IRS vector control with pyrethroids is at risk from resistance to this class of insecticide, which has already been detected in multiple locations in Mozambique. It is therefore important that a high level of vigilance is maintained through continued high quality entomological and epidemiological surveillance in this region so that corrective policy changes can be implemented before insecticide resistance leads to a public health emergency. This study demonstrates that the Malaria Decision Support System [44] provides an appropriate integrated platform for conducting such surveillance.

\section{Additional material}

Additional file 1: Prevalence of infection. Prevalence of infection with $P$. falciparum in children 1 to $<15$ years of age, by districts, observed during household surveys in 2006, 2007 and 2008 in Zambézia province, Mozambique.

\section{Acknowledgements}

This project was initiated by the late Dr. Brian Sharp. This project was made possible through the support of Provincial Director of Health, Zambézia and the PMI partner RTI in the province. The programme was funded by the Innovative Vector Control Consortium through the Malaria Decision Support System project.

\section{Author details}

${ }^{1}$ National Institute of Health, Av. Eduardo Mondlane/Salvador Allende, P.O. Box 264, Maputo, Mozambique. ${ }^{2}$ London School of Hygiene \& Tropical Medicine, Keppel Street, London WC1E 7HT, UK. ${ }^{3}$ Malaria Research Programme, MRC, 491 Ridge Road, Overport, Durban, RSA. ${ }^{4}$ Liverpool School of Tropical Medicine, Pembroke Place, Liverpool. L3 5QA, UK.

\section{Authors' contributions}

All authors have read and approved the final manuscript. APA-carried out the entomological investigations and analysis and drafted the manuscript, IK and AR carried out all epidemiological analysis, helped interpret the results and contributed to writing the manuscript, NC-supported entomological work in country, VR-carried out diagnostic tests on mosquitoes from window exit traps, DM-supported field work, SC-carried out all GIS, RMassisted in design of programme, CW and AS established insecticide resistance in the field, MC-carried out conceptual design and development of MDSS, JH-input into the writing of the manuscript, MC-was responsible for the overall project.

\section{Competing interests}

The authors declare that they have no competing interests.

Received: 30 November 2010 Accepted: 2 May 2011

Published: 2 May 2011

\section{References}

1. World Health Organization: The Fifth-Eighth World Health Assembly, 2005 2005.

2. Komatsu R, Low-Beer D, Schwartlander B: Global Fund-supported programmes contribution to international targets and the Millennium Development Goals: an initial analysis. Bull World Health Organ 2007, 85:805-811.

3. Sharp BL, Ridl FC, Govender D, Kuklinski J, Kleinschmidt I: Malaria vector control by indoor residual insecticide spraying on the tropical island of Bioko, Equatorial Guinea. Malar J 2007, 6:52.

4. Kleinschmidt I, Sharp B, Benavente LE, Schwabe C, Torrez M, Kuklinski J, Morris N, Raman J, Carter J: Reduction in infection with Plasmodium falciparum one year after the introduction of malaria control interventions on Bioko Island, Equatorial Guinea. Am J Trop Med Hyg 2006, 74:972-978.

5. Sharp BL, Kleinschmidt I, Streat E, Maharaj R, Barnes KI, Durrheim DN, Ridl FC, Morris N, Seocharan I, Kunene S, La Grange JJ, Mthembu JD, Maartens F, Martin CL, Barreto A: Seven years of regional malaria control collaboration-Mozambique, South Africa, and Swaziland. Am J Trop Med Hyg 2007, 76:42-47.

6. Mufunda J, Nyarango P, Usman A, Gebremeskel T, Mebrahtu G, Ogbamariam A, Kosia A, Ghebrat Y, Gebresillosie S, Goitom S, Araya E, Andemichael G, Gebremichael A: Roll back malaria-an African success story in Eritrea. S Afr Med J 2007, 97:46-50.

7. Chanda E, Masaninga F, Coleman M, Sikaala C, Katebe C, Macdonald M, Baboo KS, Govere J, Manga L: Integrated vector management: the Zambian experience. Malar J 2008, 7:164. 
8. Hargreaves K, Koekemoer LL, Brooke BD, Hunt RH, Mthembu J, Coetzee M: Anopheles funestus resistant to pyrethroid insecticides in South Africa. Med Vet Entomol 2000, 14:181-189.

9. Casimiro S, Coleman M, Hemingway J, Sharp B: Insecticide resistance in Anopheles arabiensis and Anopheles gambiae from Mozambique. J Med Entomol 2006, 43:276-282.

10. Casimiro S, Coleman M, Mohloai P, Hemingway J, Sharp B: Insecticide resistance in Anopheles funestus (Diptera: Culicidae) from Mozambique. J Med Entomol 2006, 43:267-275.

11. Brooke BD, Kloke G, Hunt RH, Koekemoer LL, Temu EA, Taylor ME, Small G, Hemingway J, Coetzee M: Bioassay and biochemical analyses of insecticide resistance in southern African Anopheles funestus (Diptera: Culicidae). Bull Entomol Res 2001, 91:265-272.

12. Presidents Malaria Initiative. [http://www.fightingmalaria.gov/], accessed 01/102010.

13. Presidents Malaria Initiative. [http://www.fightingmalaria.gov/countries/ profiles/mozambique.html], accessed 01/102010.

14. Innovative Vector Control Consortium. [http://www.ivcc.com/projects/ mdss.htm], accessed 01/102010.

15. Gillies MT, DeMeillon B: The Anophelinae of Africa South of the Sahara Johannesburg: The South African Institute for Medical Research; 1968.

16. Gillies MT, Coetzee M: A supplement to: The Anophelinae of Africa South of the Sahara. The Anophelinae of Africa South of the Sahara Johannesburg: The South African Institute for Medical Research; 1987.

17. Scott JA, Brogdon WG, Collins FH: Identification of single specimens of the Anopheles gambiae complex by the polymerase chain reaction. Am J Trop Med Hyg 1993, 49:520-529.

18. Koekemoer LL, Kamau L, Hunt RH, Coetzee M: A cocktail polymerase chain reaction assay to identify members of the Anopheles funestus (Diptera: Culicidae) group. Am J Trop Med Hyg 2002, 66:804-811.

19. Collins FH, Mendez MA, Rasmussen MO, Mehaffey PC, Besansky NJ, Finnerty $V$ : A ribosomal RNA gene probe differentiates member species of the Anopheles gambiae complex. Am J Trop Med Hyg 1987, 37:37-41.

20. Bass C, Nikou D, Blagborough AM, Vontas J, Sinden RE, Williamson MS, Field LM: PCR-based detection of Plasmodium in Anopheles mosquitoes: a comparison of a new high-throughput assay with existing methods. Malar J 2008, 7:177.

21. Roll Back Malraia Partnership: Malaria indicator survey: basic documentation for survey design and implementation. Geneva 2005.

22. Petrarca V, Carrara GC, Di Deco MA, Petrangeli G: [Cytogenetic and biometric observations on members of the Anopheles gambiae complex in Mozambique]. Parassitologia 1984, 26:247-259.

23. Service MW: In Mosquito ecology: Field sampling methods.. 2 edition. Edited by: Service MW. New York: Elsevier; 1993:752-889.

24. Tirados I, Costantini C, Gibson G, Torr SJ: Blood-feeding behaviour of the malarial mosquito Anopheles arabiensis: implications for vector control. Med Vet Entomol 2006, 20:425-437.

25. Kweka EJ, Mwang'onde BJ, Kimaro E, Msangi S, Massenga CP, Mahande AM: A resting box for outdoor sampling of adult Anopheles arabiensis in rice irrigation schemes of lower Moshi, northern Tanzania. Malar J 2009, 8:82.

26. WHO: Indoor residual spraying: Use of indoor residual spraying for scaling up global malaria control and elimination Geneva, Switzerland; 2006.

27. Curtis CF, Jana-Kara B, Maxwell CA: Insecticide treated nets: impact on vector populations and relevance of initial intensity of transmission and pyrethroid resistance. J Vector Borne Dis 2003, 40:1-8.

28. Kleinschmidt I, Schwabe C, Shiva M, Segura JL, Sima V, Mabunda SJ, Coleman M: Combining indoor residual spraying and insecticide-treated net interventions. Am J Trop Med Hyg 2009, 81:519-524.

29. Mbogo CM, Mwangangi JM, Nzovu J, Gu W, Yan G, Gunter JT, Swalm C, Keating J, Regens JL, Shililu Jl, Githure JI, Beier JC: Spatial and temporal heterogeneity of Anopheles mosquitoes and Plasmodium falciparum transmission along the Kenyan coast. Am J Trop Med Hyg 2003, 68:734-742.

30. Kelly-Hope L, Hemingway J, McKenzie FE: Environmental factors associated with the malaria vectors Anopheles gambiae and Anopheles funestus in Kenya. Malar J 2009, 8:268.

31. Lacey LA, Lacey CM: The medical importance of riceland mosquitoes and their control using alternatives to chemical insecticides. J Am Mosq Control Assoc Suppl 1990, 2:1-93.
32. Casimiro S, Coleman M, Mohloai P, Hemingway J, Sharp B: Insecticide resistance in Anopheles funestus (Diptera: Culicidae) from Mozambique. J Med Entomol 2006, 43:267-275.

33. Hemingway J, Penilla RP, Rodriguez AD, James BM, Edge W, Rogers $H_{4}$ Rodrigez $\mathrm{MH}$ : Resistance management strategies in malaria vector mosquito control. A large-scale field trial in Southern Mexico. Pestic Sci 1997, 51:375-382.

34. Hemingway J, Ranson $\mathrm{H}$ : Insecticide resistance in insect vectors of human disease. Annu Rev Entomol 2000, 45:371-391.

35. Hemingway J, Hawkes NJ, McCarroll L, Ranson H: The molecular basis of insecticide resistance in mosquitoes. Insect Biochem Mol Biol 2004, 34:653-665.

36. Hemingway J, Beaty BJ, Rowland M, Scott TW, Sharp BL: The Innovative Vector Control Consortium: improved control of mosquito-borne diseases. Trends Parasitol 2006, 22:308-312.

37. Wondji CS, Irving H, Morgan J, Lobo NF, Collins FH, Hunt RH, Coetzee M, Hemingway J, Ranson H: Two duplicated P450 genes are associated with pyrethroid resistance in Anopheles funestus, a major malaria vector. Genome Res 2009, 19:452-459.

38. Casimiro SL, Hemingway J, Sharp BL, Coleman M: Monitoring the operational impact of insecticide usage for malaria control on Anopheles funestus from Mozambique. Malar J 2007, 6:142.

39. Casimiro S, Coleman M, Hemingway J, Sharp B: Insecticide resistance in Anopheles arabiensis and Anopheles gambiae from Mozambique. J Med Entomol 2006, 43:276-282.

40. Coleman M, Casimiro S, Hemingway J, Sharp B: Operational impact of DDT reintroduction for malaria control on Anopheles arabiensis in Mozambique. J Med Entomol 2008, 45:885-890.

41. Barnes Kl, Durrheim DN, Little F, Jackson A, Mehta U, Allen E, Dlamini SS, Tsoka J, Bredenkamp B, Mthembu DJ, White NJ, Sharp BL: Effect of artemether-lumefantrine policy and improved vector control on malaria burden in KwaZulu-Natal, South Africa. PLoS Med 2005, 2:e330.

42. Maharaj R, Mthembu DJ, Sharp BL: Impact of DDT re-introduction on malaria transmission in KwaZulu-Natal. S Afr Med J 2005, 95:871-874.

43. Hunt R, Edwardes M, Coetzee M: Pyrethroid resistance in southern African Anopheles funestus extends to Likoma Island in Lake Malawi. Parasit Vectors 2010, 3(122):122.

44. Eisen L, Coleman M, Lozano-Fuentes S, McEachen N, Orlans M, Coleman M: Multi-disease data managment system platform for vector-borne diseases. PLoS One 2011, e1016.

doi:10.1186/1475-2875-10-110

Cite this article as: Abilio et al.: The emergence of insecticide resistance in central Mozambique and potential threat to the successful indoor residual spraying malaria control programme. Malaria Journal 2011 10:110.

\section{Submit your next manuscript to BioMed Central and take full advantage of:}

- Convenient online submission

- Thorough peer review

- No space constraints or color figure charges

- Immediate publication on acceptance

- Inclusion in PubMed, CAS, Scopus and Google Scholar

- Research which is freely available for redistribution

Submit your manuscript at www.biomedcentral.com/submit
C Biomed Central 